\title{
O REGIME DE RECUPERAÇÃO FISCAL E O FUTURO DO ESTADO DO RIO DE JANEIRO
}

\author{
William Souza Passos ${ }^{1}$ \\ ORCID: https://orcid.org/0000-0003-4648-1 \\ Rodrigo Portugal ${ }^{2}$ \\ ORCID:http://orcid.org/0000-0002-9423-6959 \\ João Costa Aguiar Filho ${ }^{3}$ \\ ORCID: http://orcid.org/0000-0003-3905-3874 \\ Recebido em: 30/03/2021 \\ Publicado em: 30/06/2021
}

\section{RESUMO}

Em setembro de 2017, foi homologado com a União o Regime de Recuperação Fiscal (RRF) do estado do Rio de Janeiro (ERJ), no qual esse ente se comprometeu com um ajuste de R\$ 63 bilhões até 2020 e de R\$ 94 bilhões até 2023. Além da elevação de receitas e redução de despesas, no ajuste, atualmente em renovação com o Novo RRF, estavam previstos novos empréstimos e uma moratória de até seis anos com a União, gerando economia total estimada em R \$ 29,6 bilhões. Por isso, considerando seus efeitos para a economia fluminense, este artigo apresenta os impactos do RRF sobre a despesa de pessoal dos poderes Executivo e Judiciário, da Assembleia Legislativa do Estado do Rio de Janeiro (ALERJ), do Tribunal de Contas do Estado do Rio de Janeiro (TCE-RJ) e do Ministério Público Estadual do Rio de Janeiro (MPRJ), com foco na relação entre despesa de pessoal/receita corrente líquida (RCL), apresentando ainda a evolução do endividamento, a partir da relação dívida consolidada líquida (DCL)/RCL. Entre outros resultados, o artigo demonstra impacto positivo do RRF para o equilíbrio orçamentário do ERJ, que iniciou uma trajetória consistente de queda das despesas no primeiro quadrimestre de 2017, especialmente das despesas de pessoal do Poder Executivo, tendo retornado e permanecido no "equilíbrio financeiro" estabelecido pela Lei de Responsabilidade Fiscal (LRF) a partir do segundo quadrimestre de 2018. A conclusão é a de que as medidas são relevantes do ponto de vista fiscal e financeiro, mas podem levar ao comprometimento de direitos básicos de cidadania, da pactuação federativa e da capacidade do ERJ de ofertar políticas públicas.

PALAVRAS-CHAVE: Regime de Recuperação Fiscal; Estado do Rio de Janeiro; Orçamento público.

\section{THE FISCAL RECOVERY REGIME AND THE FUTURE OF THE STATE OF RIO DE JANEIRO}

\footnotetext{
${ }^{1}$ Doutorando em Planejamento Urbano e Regional (IPPUR/UFRJ). Pesquisador do OBPETRO. Email: geograwilliam@gmail.com.

${ }^{2}$ Doutorando em Planejamento Urbano e Regional (IPPUR/UFRJ). Pesquisador Associado do IPEA e Economista da Sudam. Email: rodrigo.portugal88@gmail.com.

${ }^{3}$ Professor de Direito Econômico e Direito Financeiro do Centro Universitário do Leste de Minas (Unileste). Doutorando em Planejamento Urbano e Regional (IPPUR/UFRJ). Email: jcosta6034@gmail.com
} 


\begin{abstract}
In September 2017, the Federal Government ratified the Fiscal Recovery Regime (RRF) of the state of Rio de Janeiro (ERJ), in which the state committed to an adjustment of R\$ 63 billion until 2020 and R $\$ 94$ billion until 2023. Besides increasing revenues and reducing expenses, the adjustment, which is currently being renewed with the New RRF, included new loans and a moratorium of up to six years with the Federal Government, generating total savings estimated at $\mathrm{R} \$ 29.6$ billion. Therefore, considering its effects on the Rio de Janeiro economy, this article presents the impacts of the RRF on the salary expenses of the Executive and Judiciary Branches, the Legislative Assembly of the State of Rio de Janeiro (ALERJ), the Audit Court of the State of Rio de Janeiro (TCE-RJ) and the State Public Ministry of Rio de Janeiro (MPRJ), focusing on the ration between salary expenses and net current revenue (RCL), also presenting the evolution of indebtedness, based on the net consolidated debt (DCL)/RCL ratio. Among other results, the article demonstrates the positive impact of the RRF for the budgetary balance of the ERJ, which began a consistent downward trajectory of expenses in the first four months of 2017, especially the salary expenses of the Executive Branch, having returned and remained in the "financial balance" established by the Fiscal Responsibility Law (LRF) as of the second four months of 2018. The conclusion is that the measures are relevant from the fiscal and financial point of view, but may lead to the compromise of basic citizenship rights, of the federative pact, and of the ERJ's capacity to offer public policies.
\end{abstract}

KEYWORDS: Fiscal Recovery Regime; State of Rio de Janeiro; Government budget.

\title{
1. INTRODUÇÃO
}

Diante do quadro de insolvência financeira, foi homologado com a União, em setembro de 2017, um acordo de recuperação fiscal para o estado do Rio de Janeiro (ERJ), o Regime de Recuperação Fiscal (RRF), no qual o ente federativo se comprometeu a fazer um ajuste de $\mathrm{R} \$ 63$ bilhões até 2020 e de $\mathrm{R} \$ 94$ bilhões até 2023. Além do reequilíbrio orçamentário pela elevação de receitas e redução de despesas, no ajuste, em processo de renovação no primeiro semestre de 2021, com a adesão do estado ao Novo RRF, estavam previstas ainda operações de crédito ( $\mathrm{R} \$ 11,1$ bilhões em novos empréstimos) e suspensão do pagamento da dívida com a União, gerando economia estimada em $\mathrm{R}$ \$29,6 bilhões.

Considerando os efeitos do acordo para a economia fluminense, este artigo pretende apresentar os impactos do RRF sobre a despesa de pessoal e o endividamento, apontando as consequências da moratória com a União, agora renovada com o Novo RRF, para o futuro do ERJ.

Para tanto, o artigo estará estruturado em três partes, além desta introdução. $\mathrm{Na}$ primeira parte será apresentada uma síntese descritiva do impacto do RRF sobre a despesa de pessoal dos poderes Executivo e Judiciário, da Assembléia Legislativa do Estado do Rio de 
Janeiro (ALERJ), do Tribunal de Contas do Estado do Rio de Janeiro (TCE-RJ) e do Ministério Público Estadual do Rio de Janeiro (MPRJ), com foco na relação despesa de pessoal/receita corrente líquida (RCL), mas apresentando ainda a evolução da relação dívida consolidada líquida (DCL)/RCL. Na segunda parte será destacada a vinculação do atual quadro de dificuldades financeiras dos entes estaduais à repactuação do federalismo brasileiro pós-1988, que se desdobrou num sufocamento fiscal crônico no pós-Plano Real. Na terceira e última parte, as considerações finais serão acompanhadas de apontamentos das consequências para o futuro do ERJ da necessidade permanente, a curto e médio prazo, de socorro financeiro da União, agora renovado com a adesão em processo ao Novo RRF.

\section{A ADESÃO AO RRF (2017-2020), O QUADRO FINANCEIRO DO ERJ E O NOVO RRF (2021-2031)}

Aprovado pela Lei Complementar (LC) n. ${ }^{o}$ 159/2017, o RRF foi criado sob a justificativa de socorrer os estados ${ }^{4}$ em situação de grave desequilíbrio financeiro, fornecendo os instrumentos necessários para o ajuste de suas despesas e aprofundando a imposição da Lei de Responsabilidade Fiscal (LRF, LC n. ${ }^{\circ}$ 101/2000), que não previa a oferta de suporte para o retorno à trajetória de equilíbrio fiscal.

Por definição, o RRF, encerrado em 2020, considerava situação de grave desequilíbrio financeiro (i) RCL anual inferior à dívida consolidada ao final do exercício anterior; (ii) somatório das despesas com pessoal, juros e amortizações, igual ou superior a 70\% da RCL; e (iii) valor total das obrigações maior que as disponibilidades de caixa. Para aderir ao RRF, o estado candidato necessitava estar enquadrado nestes três requisitos. Por isso, apenas o ERJ teve a adesão ao RRF aprovada, apesar das candidaturas também do Rio Grande do Sul e de Minas Gerais.

O prazo máximo de vigência do RRF era de 72 meses (36 meses com prorrogação de mais 36 meses), com possibilidade de encerramento antecipado caso o beneficiário atingisse a estabilização da dívida líquida ou descumprisse as vedações da LC n. ${ }^{\circ}$ 159/2017, que bloqueava a concessão de reajustes a servidores públicos e militares acima da revisão anual constitucional; o aumento de despesas com contratação de pessoal, a criação de novos cargos, a alteração de estrutura de carreira ou concessão de benefícios trabalhistas; a criação de nova despesa obrigatória permanente ou o reajuste destas despesas acima do Índice Nacional de

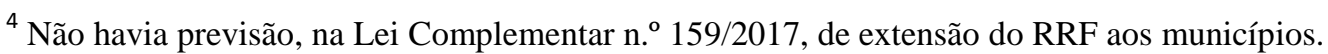


Preços ao Consumidor Amplo (IPCA) ${ }^{5}$, ou da variação anual da RCL; a ampliação ou concessão de novos incentivos ou benefícios tributários; e a contratação de operações creditícias não previstas.

Durante a vigência do RRF, o estado beneficiado esteve sujeito ao monitoramento pelo Conselho de Supervisão do Regime, condição que deve permanecer com o Novo RRF, composto por representantes do então Ministério da Fazenda, do Tribunal de Contas da União e do próprio estado em recuperação.

Além da mitigação da burocracia imposta pela legislação (LC n. ${ }^{\circ} 159 / 2017$, LC n. $^{\circ}$ 101/2000 e Capítulo II do Título VI da Constituição Federal de 1988 - CF 1988) para a captação de novos recursos, o RRF beneficiava o estado contemplado com a suspensão do pagamento das prestações das dívidas contraídas com o Tesouro Nacional por um prazo máximo de 36 meses, com o retorno suavemente escalonado da cobrança das parcelas, em caso de prorrogação, até a integralização da amortização ao final do RRF.

As medidas de ajuste (obrigatórias e adicionais) previstas no Plano de Recuperação Fiscal do Estado do Rio de Janeiro (PRF do ERJ) - documento elaborado para adesão ao RRF e composto pelo diagnóstico da situação de desequilíbrio financeiro e pelo detalhamento das medidas de ajuste, com os impactos esperados e os prazos de adoção - estavam divididas em aumento de receitas e redução de despesas para o período 2017-2022, incluídos os novos cálculos para o serviço da dívida e as operações de crédito a contratar. Juntas, aumento de receitas e redução de despesas somariam, nos seis anos previstos, um total de R \$ 94 bilhões.

Do lado da receita, estavam previstas a revisão de incentivos fiscais, a modernização da gestão fazendária, o aumento de alíquotas tributárias, a revisão do preço mínimo do petróleo e gás ${ }^{6}$, a receita de outorgas ${ }^{7}$, o aumento da contribuição previdenciária e a alienação de imóveis do Rioprevidência ${ }^{8}$, o Fundo Único de Previdência Social do Estado do Rio de Janeiro.

\footnotetext{
${ }^{5}$ Medido pelo IBGE (Instituto Brasileiro de Geografia e Estatística) e considerado o índice oficial de inflação do país.

${ }^{6}$ O preço mínimo do petróleo e gás é calculado pela média mensal do preço do petróleo tipo brent, em dólares por barril, multiplicado pelo diferencial de qualidade do petróleo nacional. A Resolução no 703/2017 da Agencia Nacional do Petróleo - ANP, no entanto, abortou a previsão de revisão do preço mínimo do petróleo e gás pelo PRF do ERJ.

${ }^{7}$ O PRF do ERJ previa a atualização das concessões de serviços públicos de transporte coletivo intermunicipal e o aumento na arrecadação das licitações de outorgas para a otimização de receitas.

${ }^{8}$ O PRF do ERJ previa o repasse de imóveis pertencentes ao patrimônio do ERJ ao Rioprevidência, para que este órgão promovesse alienações destes imóveis e daqueles já incluídos anteriormente em sua carteira (Anexo 23 do PRF do ERJ).
} 
Já do lado da despesa, foi estipulado o enquadramento da despesa de pessoal à Lei do Teto dos Gastos (LC Estadual n. ${ }^{\circ}$ 176/2017), a auditoria previdenciária e a reestruturação administrativa. Os impactos das medidas de ajuste com o aumento de receitas e redução de despesas estão apresentados nas tabelas 1 e 2 a seguir:

Tabela 01 - Impacto das medidas de ajuste com o aumento de receitas

\begin{tabular}{|c|c|c|c|}
\hline \multirow{2}{*}{$\begin{array}{c}\text { Aumento de Receita } \\
\text { Em RS milhões }\end{array}$} & \multicolumn{3}{|c|}{$\begin{array}{l}\text { Impacto Esperado das Demais Medidas de Ajuste de } \\
\text { Receita }\end{array}$} \\
\hline & Impacto 3 anos & Impacto +3 anos & Total RRF \\
\hline Tributárias & 9.949 & 11.425 & 21.374 \\
\hline Petróleo e Gás & 7.887 & 9.895 & 17.782 \\
\hline Operação Crédito & 8.059 & 0 & 8.059 \\
\hline Administrativas & 2.881 & 2.165 & 5.046 \\
\hline Pessoal & 1.979 & 1.597 & 3.576 \\
\hline Patrimônio & 2.905 & -390 & 2.515 \\
\hline Total Geral & 33.660 & 24.691 & 58.351 \\
\hline
\end{tabular}

Fonte: Plano de Recuperação Fiscal do Estado do Rio de Janeiro.

Tabela 02 - Impacto das medidas de ajuste com a redução de despesas

\begin{tabular}{lrrr}
\hline Redução de Despesa & \multicolumn{3}{c}{ Impacto Esperado das Demais Medidas de Ajuste de Despesa } \\
\hline \multicolumn{1}{c}{ Em RS milhões } & Impacto 3 anos & Impacto + 3 anos & Total RRF \\
\hline Pessoal & 2.685 & 19.689 & 22.374 \\
Dívida & 29.400 & -9.695 & 19.705 \\
Petróleo e Gás & -1.122 & -1.587 & -2.709 \\
Tributárias & -2.330 & -3.024 & -5.353 \\
Administrativa & 747 & 1.269 & 2.016 \\
$\quad$ Total Geral & $\mathbf{2 9 . 3 8 1}$ & $\mathbf{6 . 6 5 1}$ & $\mathbf{3 6 . 0 3 3}$ \\
\hline
\end{tabular}

Fonte: Plano de Recuperação Fiscal do Estado do Rio de Janeiro. 
No que diz respeito às receitas tributárias, estas vinham "em uma trajetória descendente de 2013 a 2015, com queda real acumulada em R\$ 3,6 bilhões"”. Em função disso, o PRF do ERJ projetou alterações na legislação que trata dos tributos e medidas administrativas no sentido do aumento da arrecadação. O ICMS, alterado pela Lei Estadual

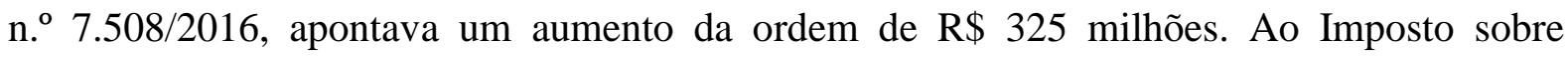
Transmissão Causa-Mortis e Doações de Qualquer Natureza - ITD, foram propostas modificações nas faixas de isenção, reduzindo-as de 100 mil UFIRs ${ }^{10}$ para 15 mil UFIRs. Adicionalmente, foram ainda planejadas a modernização da administração fazendária, a revisão dos incentivos fiscais e a revisão do Repetro, o Regime de Tributação Diferenciado das atividades de exploração ou produção de petróleo e gás natural.

Além disso, para atender ao cumprimento das metas, o PRF do ERJ impõe, como medida obrigatória, a autorização da privatização de empresas dos setores financeiro, de energia, saneamento e outros, o que, na prática, no caso do ERJ, significa a privatização da Cedae - Companhia Estadual de Águas e Esgotos (Lei Estadual n. ${ }^{\text { } ~ 7.529 / 2017) ~}{ }^{11}$; a instituição, se cabível, do Regime de Previdência Complementar (Lei Estadual n. ${ }^{\circ}$ 6.243/2012); a Reforma das Pensões (Lei Estadual n. ${ }^{\text {o } 7.628 / 2017) ; ~ a ~ R e v i s a ̃ o ~ d e ~ B e n e f i ́ c i o s ~}$ Fiscais - Fundo Estadual de Equilíbrio Fiscal - FEEF (Lei Estadual n. ${ }^{\text {o }}$ 7.428/16, alterada pela Lei Estadual n. ${ }^{\circ}$ 7.659/17); o Limite de Crescimento da Despesa (LC Estadual n. ${ }^{\circ}$ 176/2017); e a autorização para os leilões de pagamento em paralelo a proibição de saques de depósitos judiciais (Lei Estadual n ${ }^{\circ}$ 7.629/2017).

Todas essas medidas de ajuste, assim como a definição de equilíbrio financeiro do RRF, no que diz respeito aos limites de despesa de pessoal, tomam como base o que determina o artigo 169 da CF 1988, detalhado nas duas tabelas a seguir:

\footnotetext{
${ }^{9}$ Segundo a Nota $n^{\circ}$ 1/2017/SURIN/STN/MF-DF, que contém o relatório denominado "Diagnóstico do Rio de Janeiro", elaborado por uma Comissão Técnica coordenada pela Secretaria do Tesouro Nacional (STN), composta de técnicos da STN, da Procuradoria Geral da Fazenda Nacional (PGFN), do Ministério do Planejamento, Desenvolvimento e Gestão (MP) e da Secretaria de Previdência, datado de 05 de janeiro de 2017, que orientou a elaboração do PRF para o Estado.

${ }^{10}$ Unidades Fiscais de Referência, no exercício de 2021 cotada a R \$3,7053 a unidade, de acordo com a Resolução SEFAZ n. ${ }^{\circ}$ 190/2020.

11 No momento, a aplicação da Lei Estadual n. ${ }^{0}$ 7.529/2017 está suspensa pela Ação Direta de Inconstitucionalidade (ADI) n. 5683.
} 
Tabela 03 - Limites de despesas de pessoal para os entes (\% da RCL)

\begin{tabular}{lcccc}
\hline \multirow{2}{*}{$\begin{array}{c}\text { Esfera de } \\
\text { Governo }\end{array}$} & \% da RCL & \multicolumn{3}{c}{ Limite em relação ao \% da RCL } \\
\cline { 3 - 5 } & & Máximo & Prudencial & Alerta \\
\hline Federal & 50,00 & 100,00 & 95,00 & 90,00 \\
Estadual & 60,00 & 100,00 & 95,00 & 90,00 \\
Municipal & 60,00 & 100,00 & 95,00 & 90,00 \\
\hline
\end{tabular}

Fonte: Elaboração própria com base no caput do art. 169 da CF 1988 e nos arts. 19 e 20 da LRF.

Tabela 04 - Limites para os entes e seus poderes e órgãos (\% da RCL)

\begin{tabular}{|c|c|c|c|c|}
\hline \multirow{2}{*}{$\begin{array}{l}\text { Esfera de } \\
\text { Governo }\end{array}$} & \multirow{2}{*}{ Poder/Órgão } & \multicolumn{3}{|c|}{ Limite } \\
\hline & & Máximo & Prudencial & Alerta \\
\hline \multirow{4}{*}{ Federal } & $\begin{array}{l}\text { Poder Legislativo, incluindo o Tribunal } \\
\text { de Contas da União }\end{array}$ & 2,50 & 2,38 & 2,25 \\
\hline & Poder Judiciário & 6,00 & 5,70 & 5,40 \\
\hline & Poder Executivo & 40,90 & 38,86 & 36,81 \\
\hline & Ministério Público da União & 0,60 & 0,57 & 0,54 \\
\hline \multirow{4}{*}{ Estadual } & $\begin{array}{l}\text { Poder Legislativo, incluindo o Tribunal } \\
\text { de Contas do Estado }\end{array}$ & 3,00 & 2,85 & 2,71 \\
\hline & Poder Judiciário & 6,00 & 5,70 & 5,42 \\
\hline & Poder Executivo & 49,00 & 46,55 & 44,22 \\
\hline & Ministério Público dos Estados & 2,00 & 1,90 & 1,81 \\
\hline \multirow{2}{*}{ Municipal } & $\begin{array}{l}\text { Legislativo, incluindo o Tribunal de } \\
\text { Contas do Município, quando houver }\end{array}$ & 6,00 & 5,70 & 5,42 \\
\hline & Poder Executivo & 54,00 & 51,30 & 48,74 \\
\hline
\end{tabular}

Fonte: Elaboração própria com base no caput do art. 169 da CF 1988 e nos arts. 19 e 20 da LRF.

A cada bimestre, os Tribunais de Contas Estaduais (TCEs) têm que ser informados sobre os gastos da administração de cada ente. Quando as despesas atingem 90\% da RCL (limite de alerta), os TCEs enviam um comunicado aos entes federados. Quando atingem 
95\% da RCL (limite prudencial), sugerem um conjunto de medidas de contenção de despesas - por exemplo, a não concessão de reajustes aos servidores. E quando atingem 100\% da RCL (limite máximo), as transferências da União aos estados e municípios, de caráter não obrigatório pela CF 1988, são suspensas.

No caso do ERJ, o orçamento aprovado para o exercício 2021 prevê um déficit de cerca de $\mathrm{R} \$ 20,3$ bilhões ( $\mathrm{R} \$$ 69,2 bilhões em receitas e $\mathrm{R} \$$ 89,5 bilhões em despesas), tendo as pastas da Segurança Pública (R\$ 11,9 bilhões), Educação (R \$ 8,5 bilhões), Saúde (R \$ 7,2 bilhões), Transportes ( $\mathrm{R} \$ 1,3$ bilhão) e Ambiente ( $\mathrm{R} \$ 1,3$ bilhão), os cinco maiores orçamentos (Lei n. ${ }^{\circ}$ 9000/2020).

No entanto, é importante destacar que o ERJ encerrou o primeiro quadrimestre de 2020 com despesas de pessoal do Poder Executivo de apenas 39,6\% da RCL (o limite máximo é de 49,0\% da RCL, segundo os incisos I, II e III do artigo 20 da LRF), numa trajetória de queda progressiva desde a entrada, em 2017, no RRF. No último quadrimestre antes do ingresso no regime fiscal encerrado em $2020^{12}$ (o primeiro quadrimestre de 2017), a despesa de pessoal do Poder Executivo do ERJ alcançava 59,4\% da RCL, como apresentado na Tabela 05.

Tabela 05 - Despesa de pessoal do Poder Executivo do ERJ/RCL (em R\$) - 1. o quadrimestre de 2017 ao $1 .^{\circ}$ quadrimestre de 2020

\begin{tabular}{|c|c|c|c|c|c|c|}
\hline & \multicolumn{6}{|c|}{2017} \\
\hline & \multicolumn{2}{|c|}{ 1. ${ }^{\circ}$ Quadrimestre } & \multirow{2}{*}{$\begin{array}{c}\text { 2. }{ }^{\circ} \text { Quadrimestre } \\
\text { Valor em R\$ }\end{array}$} & \multicolumn{3}{|c|}{ 3. ${ }^{\circ}$ Quadrimestre } \\
\hline & Valor em R\$ & \% da RCL & & \% da RCL & Valor em R\$ & \% da RCL \\
\hline RCL & 47.619 .289 .948 & & 46.854 .486 .687 & & 50.194 .044 .675 & \\
\hline \multirow[t]{4}{*}{ Pessoal } & 28.264 .951 .505 & $\mathbf{5 9 , 4 \%}$ & 28.607 .177 .593 & $61,1 \%$ & 28.741 .803 .889 & $57,3 \%$ \\
\hline & \multicolumn{6}{|c|}{2018} \\
\hline & \multicolumn{2}{|c|}{ 1. ${ }^{\circ}$ Quadrimestre } & \multicolumn{2}{|c|}{ 2. ${ }^{\circ}$ Quadrimestre } & \multicolumn{2}{|c|}{ 3. ${ }^{\circ}$ Quadrimestre } \\
\hline & Valor em R\$ & $\%$ da RCL & Valor em R\$ & \% da RCL & Valor em R\$ & \% da RCL \\
\hline RCL & 52.260 .892 .992 & & 55.866 .344 .547 & & 58.290 .777 .944 & \\
\hline \multirow[t]{3}{*}{ Pessoal } & 29.018 .617 .845 & $55,5 \%$ & 26.094 .244 .385 & $46,7 \%$ & 21.774 .752 .857 & $37,4 \%$ \\
\hline & \multicolumn{6}{|c|}{2019} \\
\hline & \multicolumn{2}{|c|}{ 1. ${ }^{\circ}$ Quadrimestre } & \multicolumn{2}{|c|}{ 2. ${ }^{\circ}$ Quadrimestre } & \multicolumn{2}{|c|}{ 3. ${ }^{\circ}$ Quadrimestre } \\
\hline
\end{tabular}

\footnotetext{
${ }^{12}$ Embora homologado com a União em setembro de 2017, o RRF teve início em maio daquele ano.
} 


\begin{tabular}{lcccccc}
\hline & Valor em R\$ & \% da RCL & Valor em R\$ & \% da RCL & Valor em R\$ & \% da RCL \\
RCL & 59.577 .649 .677 & & 57.188 .773 .713 & & 58.566 .003 .981 & \\
Pessoal & 22.260 .351 .372 & $\mathbf{3 7 , 4 \%}$ & 22.757 .156 .586 & $\mathbf{3 9 , 8 \%}$ & 23.019 .690 .204 & $\mathbf{3 9 , 3 \%}$ \\
\hline
\end{tabular}

2020

1. ${ }^{\circ}$ Quadrimestre

\begin{tabular}{lcc}
\hline & Valor em R\$ & \% da RCL \\
RCL & 58.853 .336 .343 & \\
Pessoal & 23.291 .660 .815 & $\mathbf{3 9 , 6 \%}$
\end{tabular}

Fonte: Relatório de Gestão Fiscal, Portal Transparência Fiscal do Governo do Estado do Rio de Janeiro (RIO DE JANEIRO, 2021). Nota: A Defensoria Pública Geral do Estado - DPGE está incluída no demonstrativo da despesa com pessoal do Poder Executivo.

Como é possível observar no quadro anterior e no Gráfico 01, a seguir, as despesas de pessoal do Poder Executivo, com algumas poucas oscilações, iniciaram uma trajetória consistente de queda desde a entrada do ERJ no RRF, no primeiro quadrimestre de 2017 , tendo retornado e permanecido no "equilíbrio financeiro" da LRF a partir do segundo quadrimestre de 2018 .

Gráfico 01 - Despesa de pessoal do Poder Executivo do ERJ/RCL - 1. ${ }^{\circ}$ quadrimestre de 2017 ao $1 .^{\circ}$ quadrimestre de 2020

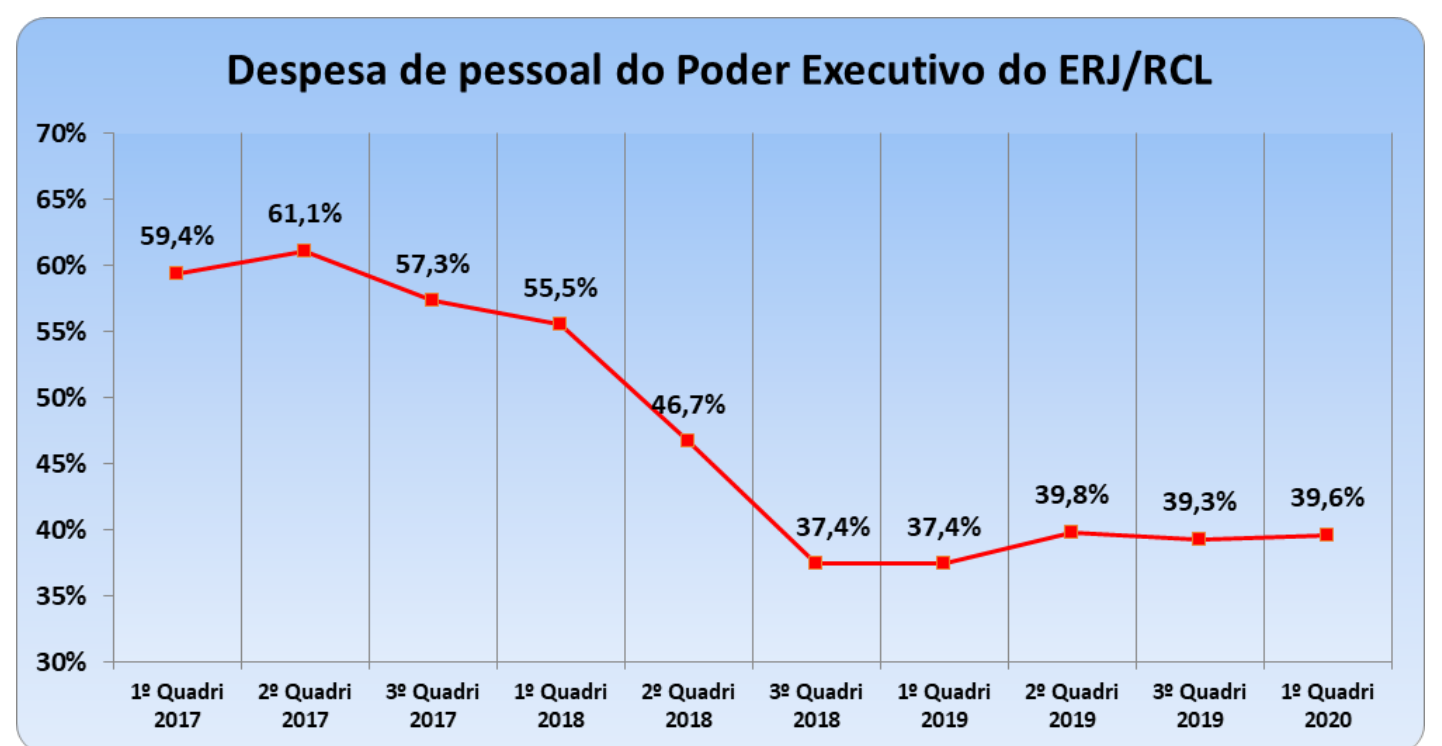

Fonte: Relatório de Gestão Fiscal, Portal Transparência Fiscal do Governo do Estado do Rio de Janeiro (RIO DE JANEIRO, 2021).

O último dado disponível no momento da elaboração deste artigo foi o do primeiro quadrimestre de 2020, quando as despesas de pessoal do Poder Executivo registraram 39,6\% 
da RCL, mas é fundamental considerar que a partir do segundo quadrimestre de 2020 o ERJ começou a sentir os efeitos da pandemia causada pelo Sars-CoV-2, o novo coronavírus, que paralisou parte da economia e reduziu significativamente o ritmo da maioria das atividades, o que pode ter impactado o orçamento, as estimativas e a execução de receitas e despesas e, com isso, o equilíbrio do balanço financeiro do ERJ no restante do exercício de 2020, prolongando-se pelo exercício de 2021.

No que diz respeito aos demais poderes (Judiciário, ALERJ, TCE-RJ e MPRJ), como se pode observar nas tabelas 06, 07, 08 e 09, todos eles já apresentavam despesas de pessoal em relação à RCL abaixo do recomendado pela LRF antes mesmo do ingresso do ERJ no RRF. Ainda assim, com exceção do MPRJ, os demais poderes colaboraram no esforço de reequilíbrio do orçamento geral do ERJ, baixando suas despesas proporcionais.

Tabela 06 - Despesa de pessoal do Poder Judiciário do ERJ/RCL (em R\$) - $1 .^{\circ}$ quadrimestre de 2017 ao $1 .^{\circ}$ quadrimestre de 2020

\begin{tabular}{|c|c|c|c|c|c|c|}
\hline & \multicolumn{6}{|c|}{2017} \\
\hline & \multicolumn{2}{|c|}{ 1. ${ }^{\circ}$ Quadrimestre } & \multirow{2}{*}{$\begin{array}{c}\text { 2. }{ }^{\circ} \text { Quadrimestre } \\
\text { Valor em R\$ }\end{array}$} & \multicolumn{3}{|c|}{ 3. ${ }^{\circ}$ Quadrimestre } \\
\hline & Valor em R\$ & \% da RCL & & \% da RCL & Valor em R\$ & $\%$ da RCL \\
\hline RCL & 47.619.289.948 & & 46.854 .486 .687 & & 50.194 .044 .675 & \\
\hline \multirow[t]{4}{*}{ Pessoal } & 2.756.718.597 & $5,8 \%$ & 2.773 .025 .832 & $5,9 \%$ & 2.772 .097 .754 & $5,5 \%$ \\
\hline & \multicolumn{6}{|c|}{2018} \\
\hline & \multicolumn{2}{|c|}{ 1. ${ }^{\circ}$ Quadrimestre } & \multicolumn{2}{|c|}{ 2. ${ }^{\circ}$ Quadrimestre } & \multicolumn{2}{|c|}{ 3. ${ }^{\circ}$ Quadrimestre } \\
\hline & Valor em R\$ & \% da RCL & Valor em R\$ & \% da RCL & Valor em R\$ & $\%$ da RCL \\
\hline RCL & 52.260 .892 .992 & & 55.866 .344 .547 & & 58.290 .777 .944 & \\
\hline \multirow[t]{4}{*}{ Pessoal } & 2.796 .499 .496 & $5,4 \%$ & 2.817 .622 .621 & $5,0 \%$ & 2.818.901.497 & $4,8 \%$ \\
\hline & \multicolumn{6}{|c|}{2019} \\
\hline & \multicolumn{2}{|c|}{ 1. ${ }^{\circ}$ Quadrimestre } & \multicolumn{2}{|c|}{ 2. ${ }^{\circ}$ Quadrimestre } & \multicolumn{2}{|c|}{ 3. ${ }^{\circ}$ Quadrimestre } \\
\hline & Valor em R\$ & $\%$ da RCL & Valor em R\$ & $\%$ da RCL & Valor em R\$ & $\%$ da RCL \\
\hline RCL & 59.577 .649 .677 & & 57.188 .773 .713 & & 58.566 .003 .981 & \\
\hline \multirow[t]{4}{*}{ Pessoal } & 2.840 .828 .514 & $4,8 \%$ & 2.931 .834 .443 & $5,1 \%$ & 2.829 .706 .850 & $4,8 \%$ \\
\hline & \multicolumn{6}{|c|}{2020} \\
\hline & \multicolumn{2}{|c|}{ 1. ${ }^{\circ}$ Quadrimestre } & & & & \\
\hline & Valor em R\$ & \% da RCL & & & & \\
\hline
\end{tabular}


Pessoal $2.813 .232 .780 \quad \mathbf{4 , 8} \%$

Fonte: Relatório de Gestão Fiscal, Portal Transparência Fiscal do Governo do Estado do Rio de Janeiro.

Tabela 07 - Despesa de pessoal da ALERJ/RCL (em R\$) - 1. ${ }^{\circ}$ quadrimestre de 2017 ao $1 .^{\circ}$ quadrimestre de 2020

\begin{tabular}{|c|c|c|c|c|c|c|}
\hline & \multicolumn{6}{|c|}{2017} \\
\hline & \multicolumn{2}{|c|}{ 1. ${ }^{\circ}$ Quadrimestre } & \multirow{2}{*}{$\begin{array}{c}2 .^{\circ} \text { Quadrimestre } \\
\text { Valor em R\$ }\end{array}$} & \multicolumn{3}{|c|}{ 3. ${ }^{\circ}$ Quadrimestre } \\
\hline & Valor em R\$ & \% da RCL & & \% da RCL & Valor em R\$ & $\%$ da RCL \\
\hline RCL & 47.619.289.948 & & 46.854 .486 .687 & & 50.194 .044 .675 & \\
\hline \multirow[t]{4}{*}{ Pessoal } & 676.976 .839 & $1,4 \%$ & 674.059 .187 & $1,4 \%$ & 681.986 .730 & $1,4 \%$ \\
\hline & \multicolumn{6}{|c|}{2018} \\
\hline & \multicolumn{2}{|c|}{ 1. ${ }^{\circ}$ Quadrimestre } & \multicolumn{2}{|c|}{ 2. ${ }^{\circ}$ Quadrimestre } & \multicolumn{2}{|c|}{ 3. ${ }^{\circ}$ Quadrimestre } \\
\hline & Valor em R\$ & \% da RCL & Valor em R\$ & \% da RCL & Valor em R\$ & $\%$ da RCL \\
\hline RCL & 52.260 .892 .992 & & 55.866 .344 .547 & & 58.290 .777 .944 & \\
\hline \multirow[t]{4}{*}{ Pessoal } & 694.110 .483 & $1,3 \%$ & 721.988 .245 & $1,3 \%$ & 741.449 .808 & $1,3 \%$ \\
\hline & \multicolumn{6}{|c|}{2019} \\
\hline & \multicolumn{2}{|c|}{ 1. ${ }^{\circ}$ Quadrimestre } & \multicolumn{2}{|c|}{ 2. ${ }^{\circ}$ Quadrimestre } & \multicolumn{2}{|c|}{ 3. ${ }^{\circ}$ Quadrimestre } \\
\hline & Valor em R\$ & \% da RCL & Valor em R\$ & \% da RCL & Valor em R\$ & \% da RCL \\
\hline RCL & 59.577 .649 .677 & & 57.188 .773 .713 & & 58.566 .003 .981 & \\
\hline \multirow[t]{4}{*}{ Pessoal } & 762.656 .201 & $1,3 \%$ & 706.164 .284 & $1,2 \%$ & 634.824 .773 & $1,1 \%$ \\
\hline & \multicolumn{6}{|c|}{2020} \\
\hline & \multicolumn{2}{|c|}{ 1. ${ }^{\circ}$ Quadrimestre } & & & & \\
\hline & Valor em R\$ & \% da RCL & & & & \\
\hline RCL & 58.853 .336 .343 & & & & & \\
\hline Pessoal & 587.275 .514 & $1,0 \%$ & & & & \\
\hline
\end{tabular}

Fonte: Relatório de Gestão Fiscal, Portal Transparência Fiscal do Governo do Estado do Rio de Janeiro. 
Tabela 08 - Despesa de pessoal do TCE-RJ/RCL (em R\$) - $1 .^{\circ}$ quadrimestre de 2017 ao $1 .^{\circ}$ quadrimestre de 2020

\begin{tabular}{|c|c|c|c|c|c|c|}
\hline & \multicolumn{6}{|c|}{2017} \\
\hline & \multicolumn{2}{|c|}{ 1. ${ }^{\circ}$ Quadrimestre } & \multirow{2}{*}{$\begin{array}{c}\text { 2. }{ }^{\circ} \text { Quadrimestre } \\
\text { Valor em R\$ }\end{array}$} & \multicolumn{3}{|c|}{ 3. ${ }^{\circ}$ Quadrimestre } \\
\hline & Valor em R\$ & \% da RCL & & \% da RCL & Valor em R\$ & \% da RCL \\
\hline RCL & 47.619.289.948 & & 46.854 .486 .687 & & 50.194 .044 .675 & \\
\hline \multirow[t]{4}{*}{ Pessoal } & 550.176 .982 & $1,2 \%$ & 543.292 .883 & $1,2 \%$ & 537.250 .211 & $1,1 \%$ \\
\hline & \multicolumn{6}{|c|}{2018} \\
\hline & \multicolumn{2}{|c|}{ 1. ${ }^{\circ}$ Quadrimestre } & \multicolumn{2}{|c|}{ 2. ${ }^{\circ}$ Quadrimestre } & \multicolumn{2}{|c|}{ 3. ${ }^{\circ}$ Quadrimestre } \\
\hline & Valor em R\$ & \% da RCL & Valor em R\$ & $\%$ da RCL & Valor em R\$ & \% da RCL \\
\hline RCL & 52.260 .892 .992 & & 55.866 .344 .547 & & 58.290 .777 .944 & \\
\hline \multirow[t]{4}{*}{ Pessoal } & 536.069 .249 & $1,0 \%$ & 533.717 .870 & $1,0 \%$ & 537.569 .392 & $0,9 \%$ \\
\hline & \multicolumn{6}{|c|}{2019} \\
\hline & \multicolumn{2}{|c|}{ 1. ${ }^{\circ}$ Quadrimestre } & \multicolumn{2}{|c|}{ 2. ${ }^{\circ}$ Quadrimestre } & \multicolumn{2}{|c|}{ 3. ${ }^{\circ}$ Quadrimestre } \\
\hline & Valor em R\$ & \% da RCL & Valor em R\$ & \% da RCL & Valor em R\$ & \% da RCL \\
\hline RCL & 59.577 .649 .677 & & 57.188 .773 .713 & & 58.566 .003 .981 & \\
\hline Pessoal & 528.380 .317 & $0,9 \%$ & 536.633 .086 & $0,9 \%$ & 509.077 .565 & $0,9 \%$ \\
\hline
\end{tabular}

1. ${ }^{\circ}$ Quadrimestre

\begin{tabular}{lcc}
\hline & Valor em R\$ & \% da RCL \\
;a & 58.853 .336 .343 & \\
Pessoal & 493.230 .652 & $\mathbf{0 , 8 \%}$ \\
\hline
\end{tabular}

Tabela 09 - Despesa de pessoal do MPRJ/RCL (em R\$) - 1. ${ }^{\circ}$ quadrimestre de 2017 ao $1 .^{\circ}$ quadrimestre de 2020

\begin{tabular}{|c|c|c|c|c|c|c|}
\hline & \multicolumn{6}{|c|}{2017} \\
\hline & \multicolumn{2}{|c|}{ 1. ${ }^{\circ}$ Quadrimestre } & \multirow{2}{*}{$\begin{array}{c}\text { 2. }{ }^{\circ} \text { Quadrimestre } \\
\text { Valor em R\$ }\end{array}$} & \multicolumn{3}{|c|}{ 3. ${ }^{\circ}$ Quadrimestre } \\
\hline & Valor em R\$ & \% da RCL & & $\%$ da RCL & Valor em R\$ & \% da RCL \\
\hline RCL & 47.619.289.948 & & 46.854 .486 .687 & & 50.194 .044 .675 & \\
\hline \multirow[t]{3}{*}{ Pessoal } & 860.895 .056 & $1,8 \%$ & 876.337 .709 & $1,9 \%$ & 903.272 .149 & $1,8 \%$ \\
\hline & \multicolumn{6}{|c|}{2018} \\
\hline & \multicolumn{2}{|c|}{ 1. ${ }^{\circ}$ Quadrimestre } & \multicolumn{2}{|c|}{ 2. ${ }^{\circ}$ Quadrimestre } & \multicolumn{2}{|c|}{ 3. ${ }^{\circ}$ Quadrimestre } \\
\hline
\end{tabular}




\begin{tabular}{|c|c|c|c|c|c|c|}
\hline & Valor em R\$ & \% da RCL & Valor em R\$ & \% da RCL & Valor em R\$ & \% da RCL \\
\hline RCL & 52.260 .892 .992 & & 55.866 .344 .547 & & 58.290 .777 .944 & \\
\hline \multirow[t]{4}{*}{ Pessoal } & 946.180 .260 & $1,8 \%$ & 977.438 .318 & $1,7 \%$ & 972.545 .785 & $1,7 \%$ \\
\hline & \multicolumn{6}{|c|}{2019} \\
\hline & \multicolumn{2}{|c|}{ 1. ${ }^{\circ}$ Quadrimestre } & \multicolumn{2}{|c|}{ 2. ${ }^{\circ}$ Quadrimestre } & \multicolumn{2}{|c|}{ 3. ${ }^{\circ}$ Quadrimestre } \\
\hline & Valor em R\$ & \% da RCL & Valor em R\$ & $\%$ da RCL & Valor em R\$ & $\%$ da RCL \\
\hline RCL & 59.577 .649 .677 & & 57.188 .773 .713 & & 58.566 .003 .981 & \\
\hline \multirow[t]{4}{*}{ Pessoal } & 1.000 .795 .501 & $1,7 \%$ & 1.058 .836 .902 & $1,9 \%$ & 1.045 .427 .228 & $1,8 \%$ \\
\hline & \multicolumn{6}{|c|}{2020} \\
\hline & \multicolumn{2}{|c|}{ 1. ${ }^{\circ}$ Quadrimestre } & & & & \\
\hline & Valor em R\$ & \% da RCL & & & & \\
\hline RCL & 58.853 .336 .343 & & & & & \\
\hline Pessoal & 1.047.038.697 & $1,8 \%$ & & & & \\
\hline
\end{tabular}

Fonte: Relatório de Gestão Fiscal, Portal Transparência Fiscal do Governo do Estado do Rio de Janeiro.

Com isso, conclui-se que as medidas, por vezes "draconianas", impostas pelo RRF ajudaram o ERJ a retornar e permanecer, a partir de meados de 2018, na trajetória de equilíbrio financeiro estabelecida pela LRF, especialmente no que diz respeito as despesas de pessoal do Poder Executivo, principal formulador e executor de políticas públicas. No entanto, não obstante, efetivamente, tenham sido feitos cortes de pessoal, e basicamente no Executivo, como demonstrado adiante, os impactos das medidas do RRF, ano a ano, não foram suficientes para enfrentar o crescimento da dívida e outras "ações draconianas" propostas pelo RRF ao ERJ. Com isso, embora relevantes do ponto de vista fiscal e financeiro, o reequilíbrio financeiro pode levar ao comprometimento de direitos básicos de cidadania, da pactuação federativa e da capacidade do ERJ de ofertar políticas públicas.

A este respeito, a Tabela 10 sintetiza e compara a economia com a suspensão do pagamento da dívida com a União, o aumento de receitas, o corte de gastos e a obtenção de novos empréstimos bancários com garantias.

Tabela 10 - Impactos das medidas do RRF nas finanças do ERJ (2017-2020), em milhões de $\mathrm{R} \$$

\begin{tabular}{|c|c|c|c|c|}
\hline & 2017 & 2018 & 2019 & 2020 \\
\hline Suspensão do pagamento da dívida com a União & 5,000 & 9,000 & 9,000 & 6,600 \\
\hline Aumento de receitas & 1,500 & 5,200 & 6,500 & 9,400 \\
\hline
\end{tabular}




\begin{tabular}{ccccc} 
Redução de despesas & 350 & 420 & 1,000 & 3,000 \\
\hdashline Novos empréstimos bancários com garantias & 6,600 & 4,500 & - & - \\
\hline
\end{tabular}

Fonte: Portal Transparência Fiscal do Governo do Estado do Rio de Janeiro.

Como se pode observar na Tabela 10, a suspensão do pagamento da dívida com a União combinada à pressão pelas medidas de ajuste surtiu efeitos de caixa positivo no ERJ: em apenas quatro anos (2017 a 2020), as receitas fluminenses cresceram mais de seis vezes (de $\mathrm{R} \$ 1,500$ bilhão para $\mathrm{R} \$ 9,400$ bilhões), enquanto as despesas foram reduzidas em quase nove vezes (de $\mathrm{R} \$ 350$ milhões para $\mathrm{R} \$ 3,000$ bilhões).

Entretanto, apesar do retorno e permanência ao equilíbrio financeiro, como prediz a LRF, a dívida consolidada do ERJ (somando administração direta e indireta mais precatórios posteriores a 05/05/2000), mesmo com o ingresso do ente no RRF, manteve uma trajetória contínua de crescimento de seu estoque, em valores absolutos, registrando um incremento de $\mathrm{R} \$ 83,431$ bilhões entre 2016 e 2020, como se pode verificar no Gráfico 02 a seguir.

Gráfico 02 - Dívida consolidada do ERJ (em milhões de R\$) - 2016-2020

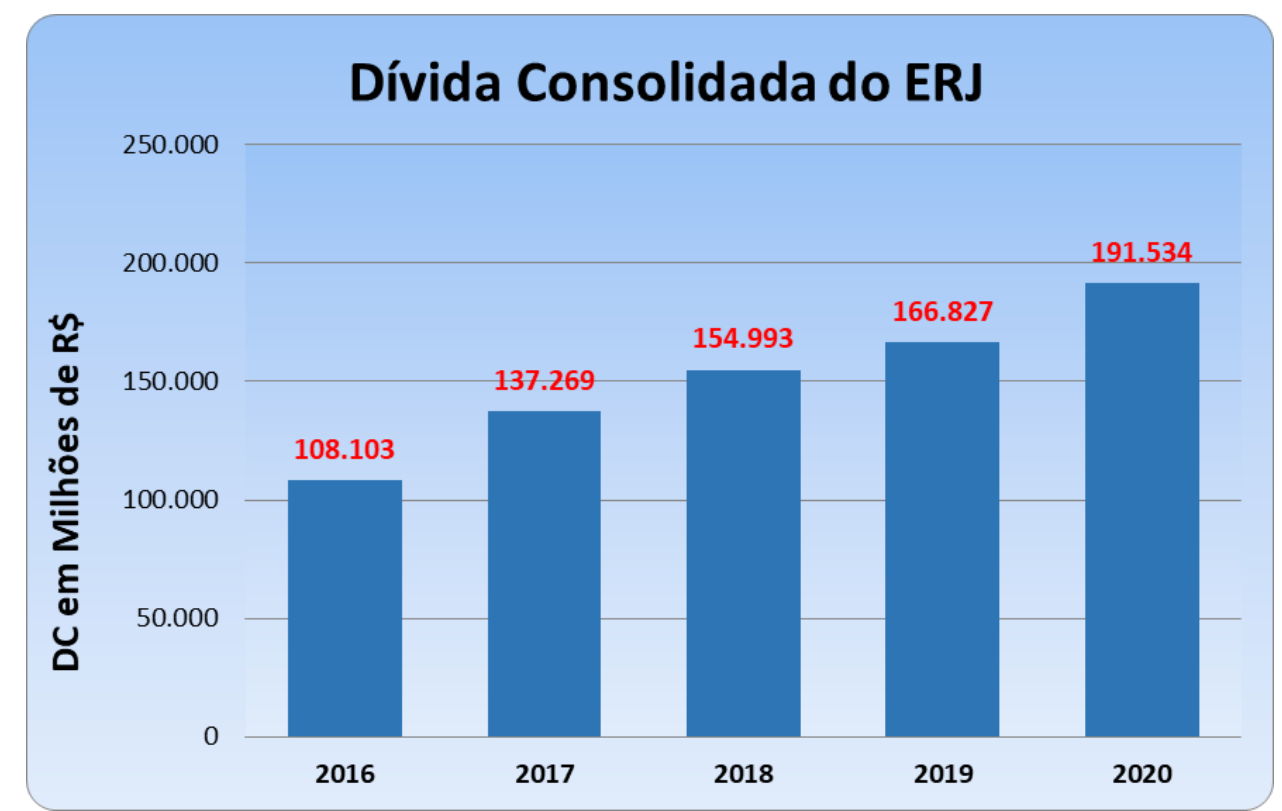

Fonte: Relatório de Gestão Fiscal, Portal Transparência Fiscal do Governo do Estado do Rio de Janeiro.

Portanto, as severas medidas de ajuste, entre elas a redução de despesas com pessoal e a suspensão do pagamento da dívida com a União, não tiveram impacto consolidado para a redução dos níveis da dívida pública estadual, suscitando que o imbróglio pode estar ao largo da LRF e das medidas estritamente fiscais e financeiras, sendo um problema que envolve a base econômica ou as capacidades governativas do Estado (MONTEIRO NETO, 2014). 
Por outra medida, quando aplicado o Índice Geral de Preços - Disponibilidade Interna (IGP-DI), da Fundação Getúlio Vargas (FGV), utilizado como referência para reajustes de tarifas do Setor Público, observa-se que o ritmo de crescimento do estoque da dívida consolidada fluminense, a partir do biênio 2018-2019, variou menos que a inflação, demonstrando impacto positivo do RRF.

Gráfico 03 - Variação percentual da dívida consolidada do ERJ - 2016-2017 a 2019-2020

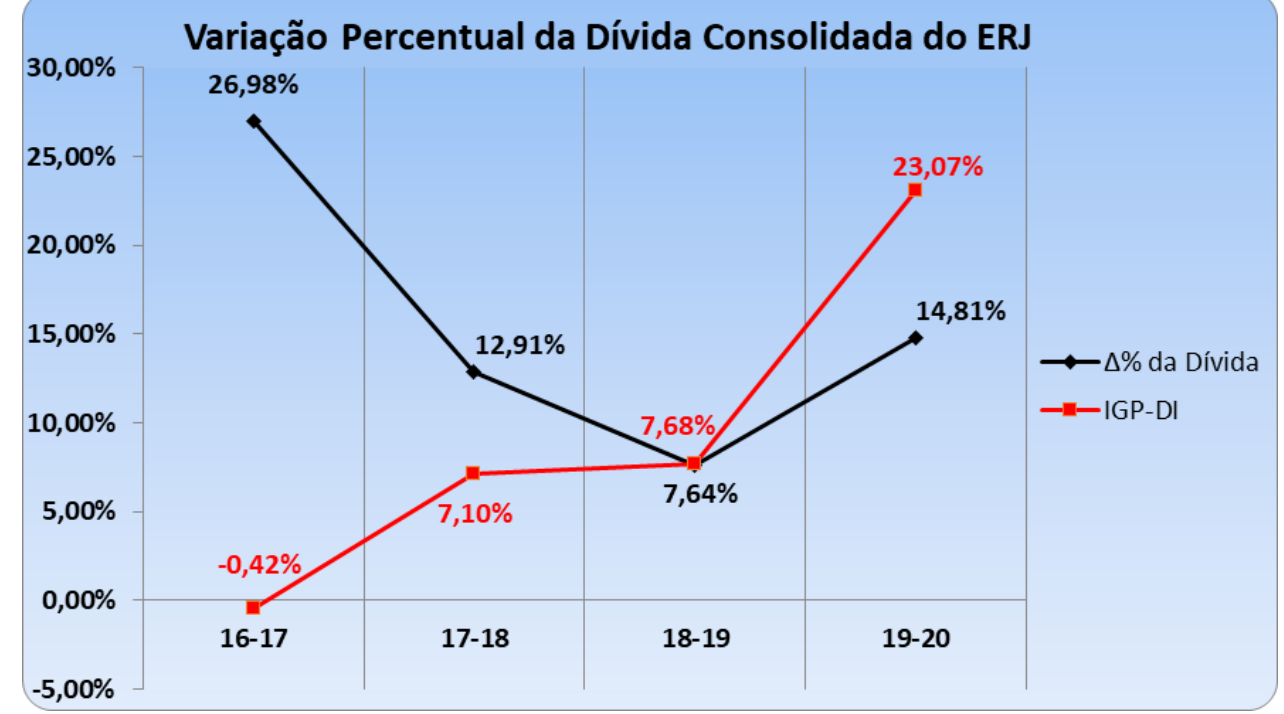

Fonte: Relatório de Gestão Fiscal, Portal Transparência Fiscal do Governo do Estado do Rio de Janeiro.

Com isso, a relação DCL/RCL do ERJ, apesar da continuidade da trajetória de crescimento, vem evoluindo num ritmo anual inferior àquele de 2016-2017, último ano antes da entrada do ente no RRF. Como se pode observar no Gráfico 04, a relação nos dois estoques saiu de 229,41\% em 2016 para 269,74\% em 2017, 262,92\% em 2018, 282,08\% em 2019 e 319,03\% em 2020, bem acima dos 200,00\% impostos pela LRF e pela Resolução no 43/2001 do Senado Federal.

Gráfico 04 - Relação DCL/RCL do ERJ - 2016-2020 


\section{X RCL do ERJ}

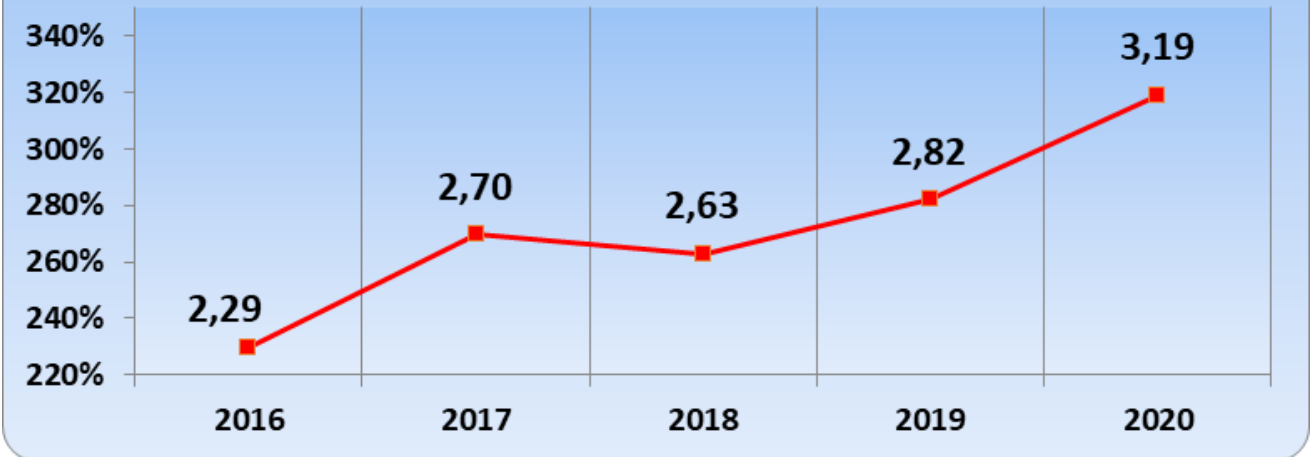

Fonte: Relatório de Gestão Fiscal, Portal Transparência Fiscal do Governo do Estado do Rio de Janeiro.

A partir de janeiro de 2021, porém, a LC n. ${ }^{\circ}$ 159/2017 foi alterada pela LC n. ${ }^{\circ}$ 178/2021, que criou o Novo RRF, com duração de 10 anos. A adesão do ERJ ao Novo RRF foi imediatamente anunciada e, no momento em que este artigo está sendo escrito, encontrase em processo. Com o prolongamento do período do acordo fiscal, segundo cálculos da Secretaria do Tesouro Nacional (STN), o ERJ poderá ter um alívio de caixa estimado em cerca de $\mathrm{R} \$ 52,5$ bilhões entre 2021 e 2029.

Na prática, o Novo RRF prevê a suspensão do pagamento da dívida do ERJ com a União nos dois primeiros anos, com a retomada gradual da amortização nos oito anos seguintes e a contrapartida de um esforço fiscal que inclui reformas previdenciária e administrativa, a implementação de um novo teto de gastos e a redução de benefícios físcais.

Para o futuro do ERJ, em que pese a manutenção do cenário de melhora do equilíbrio contábil, a adesão ao Novo RRF significará a continuidade da restrição orçamentária dos serviços públicos, em especial a saúde, segurança pública, educação e mobilidade urbana, afetando, particularmente, a parcela da população mais dependente do Setor Público, formada, sobretudo, pelos mais pobres e pessoas sob as demais situações de vulnerabilidade.

\section{A repactuação do federalismo brasileiro pós-1988 e o sufocamento fiscal dos estados pós-plano real}

O Código Tributário Nacional (Lei n. ${ }^{\circ}$ 5172/1966) deu início a um processo de concentração tributária em favor da União, desdobrado na explosão do endividamento dos estados a partir da década de 1970. 
Com o cenário hiperinflacionário da década seguinte e a repactuação do federalismo introduzida pela CF 1988, que ampliou as obrigações administrativas dos estados, os entes estaduais mergulharam num quadro de descontrole financeiro.

Por sua vez, a década de 1990 foi marcada por dois importantes momentos de renegociação da dívida dos estados com a União: em 1993, quando parte das dívidas foi renegociada por 20 anos e, em 1997, quando o governo federal assumiu a dívida de 23 estados e 182 municípios $^{13}$, alongando o prazo para 30 anos, oferecendo juros abaixo das taxas de mercado, avalizando o pagamento com recursos do ICMS $^{14}$, impondo medidas de ajuste fiscal e privatização e proibindo a emissão de qualquer tipo de título no mercado (RIGOLON; GIAMBIAGI, 1999).

Importante destacar, ao nível dos estados, que a estabilização monetária promovida pelo Plano Real, a partir de julho de 1994, além dos juros altos e da baixa atividade econômica, veio acompanhada do fim dos ganhos do "imposto inflacionário", que permitia o incremento das receitas pelo uso da correção atrelada à inflação.

Também eliminou outra importante fonte de incremento orçamentário com a criação do Proes (Programa de Incentivo à Redução da Presença do Estado na Atividade Bancária), em 1996, que promoveu a privatização, extinção, transformação em agência de fomento e o saneamento financeiro dos bancos estaduais. No caso do ERJ, o resultado foi a privatização do Banco do Estado do Rio de Janeiro (BANERJ), em junho de 1997, leiloado para o Itaú, por R\$ 311,1 milhões, em valores da época ${ }^{15}$.

Para completar o novo cenário de sufocamento fiscal dos estados no pós-Plano Real, foi sancionada, em maio de 2000, a LRF, que estabeleceu o controle dos gastos da União, estados, Distrito Federal e municípios, condicionando-os à capacidade de arrecadação dos entes federativos. A LRF também promoveu a transparência dos gastos públicos, obrigando a apresentação do detalhamento das finanças aos TCEs de cada ente ${ }^{16}$.

\footnotetext{
${ }^{13}$ Cerca de $90 \%$ da dívida renegociada pela Lei n. ${ }^{\circ}$ 9.496/1997 estava concentrada nos quatro estados mais ricos: São Paulo, Rio de Janeiro, Minas Gerais e Rio Grande do Sul (MORA, 2002).

${ }^{14}$ Imposto sobre operações relativas à circulação de mercadorias e sobre prestações de serviços de transporte interestadual, intermunicipal e de comunicação.

$15 \mathrm{O}$ processo de privatização do BANERJ foi marcado por uma série de irregularidades: manipulação de balanços e de operações contábeis, subavaliação do patrimônio e do valor de venda e favorecimento do grupo financeiro comprador. No leilão, o banco estadual fluminense foi vendido com um ágil de apenas $0,6 \% \mathrm{em}$ relação ao preço mínimo fixado e adquirido com "moedas podres" (Certificados de Privatização), que resultaram ao final, no desembolso real de apenas R \$ 200 milhões pelo Itaú. Para mais detalhes, consultar Brandão (2009).

${ }^{16}$ Apenas São Paulo e Rio de Janeiro detêm Tribunal de Contas Municipal. Os demais municípios brasileiros são obrigados a remeter o detalhamento contábil dos gastos da administração aos Tribunais de Contas do Estado.
} 
Em 2014, durante o período eleitoral, houve a alteração do cálculo das dívidas dos estados e de cerca de 180 municípios. Em vez das taxas entre $6 \%$ e $9 \%$ e da correção pelo IGP-DI, os juros foram reduzidos para $4 \%$ e as dívidas indexadas pelo IPCA, ou a Selic ${ }^{17}$, o que fosse menor ${ }^{18}$.

Apesar do alívio no caixa, vários estados e municípios entraram em crise financeira em 2016, alguns até antes (LOPREATO, 2018), em um sensível momento político e econômico no Brasil após o impeachment da presidente Dilma Roussef, tendo o ERJ apresentado o quadro mais grave, decretando estado de calamidade em novembro daquele ano (Decreto $\left.n^{\circ} 45.692 / 2016\right)$ e entrando no RRF em maio de 2017.

\section{CONSIDERAÇÕES FINAIS}

O "pacto" contraditório do federalismo brasileiro, que estabelece, com o Código Tributário Nacional, concentração da arrecadação tributária em favor da União, mas, com a CF 1988, concentração das obrigações e competências nos estados e municípios, somadas à estabilização monetária do Plano Real, a partir de julho de 1994, que eliminou os ganhos do “imposto inflacionário", à baixa atividade econômica do período pós-1994 e aos impactos do Proes, que, na prática, resultou na privatização dos bancos estaduais, no caso do ERJ o BANERJ, desdobrando-se na perda da capacidade de utilização da política monetária, limitou os entes estaduais à restrição do uso da política fiscal como o único instrumento de política macroeconômica possível.

Com isso, os estados passaram a se ver constrangidos pela necessidade de aumento contínuo das despesas correntes frente à perda progressiva da capacidade de arrecadação, resultando em sufocamento orçamentário e, consequentemente, em expansão do endividamento, renovado com os ciclos de renegociação das dívidas com a União e com as moratórias financeiras, como o RRF a partir de 2017 e, agora em 2021, o Novo RRF.

Para as instâncias estaduais, de modo especial, a tendência do federalismo brasileiro é a de que o progressivo enxugamento do Setor Público e o esvaziamento das funções do Estado, no caso dos entes estaduais, reduzidos a pouco além das polícias civis e militares, à educação de ensino médio e à intermediação do Serviço Único de Saúde (SUS) entre o

\footnotetext{
${ }^{17}$ Sistema Especial de Liquidação e de Custódia, considerada a taxa básica de juros da economia brasileira.

${ }^{18}$ Em junho de 2016, após um acordo judicial mediado pelo STF, a União alongou as dívidas estaduais por mais 20 anos com a contrapartida de inserção dos estados no teto dos gastos públicos (Emenda Constitucional no 95 (EC 95), segundo o qual as despesas não podem crescer mais do que a inflação do ano anterior, medida pelo IPCA.
} 
governo federal e seus municípios, seja agressivamente aprofundado. A pressão do lobby da Confederação Nacional dos Municípios (CNM) pela incorporação da agenda orçamentária municipalista de ampliação da descentralização e "desfederalização" do orçamento nacional em favor dos governos locais, por outro lado, sinaliza na direção do enfraquecimento e de um progressivo processo de provincialização dos estados brasileiros.

Outra importante tendência a destacar é a possibilidade da escalada da imposição de ajustes draconianos aos estados e municípios em grave crise de desfinanciamento, revelada pelo RRF e pelo Novo RRF, e ainda pelas Propostas de Emendas Constitucionais (PECs) apresentadas ou aprovadas durante o período da pandemia do novo coronavírus (Sars-CoV-2) - no Brasil, iniciado efetivamente a partir de março de 2020 -, entre elas a PEC Emergencial (PEC 186/19), que permite ao governo federal pagar, em 2021, um novo auxílio emergencial para a população vulnerável afetada pela pandemia. Como medidas compensatórias, o texto da PEC Emergencial prevê, entre outras contrapartidas, a proibição da realização de concursos públicos e o congelamento dos salários, progressões e gratificações dos servidores públicos quando as despesas de estados e municípios atingirem $95 \%$ das receitas correntes.

Neste aspecto, cabe destacar ainda a Emenda Constitucional $\mathrm{n}^{\circ} 95$ (EC 95) Emenda Constitucional do Teto dos Gastos Públicos -, que alterou a CF 1988 para instituir o Novo Regime Fiscal e influenciou a Lei do Teto dos Gastos fluminense (LC Estadual n. ${ }^{\circ}$ $176 / 2017)$

Na prática, a EC 95 impõe um severo ajuste das contas do Estado brasileiro durante 20 anos, ao limitar as despesas e investimentos aos mesmos valores gastos no ano anterior, corrigidos pela inflação medida pelo IPCA. Como, via de regra, o IPCA não reflete a inflação real da economia brasileira, registrando sempre percentuais mais baixos do que a desvalorização monetária sentida pela maior parte da população, especialmente os mais pobres, a EC 95, como desdobramento, acaba, em termos de valores reais, por reduzir os gastos e investimentos públicos ao longo dos anos.

Com isso, além do comprometimento dos direitos básicos de cidadania estabelecidos pela CF 1988, sobretudo da parcela da população mais dependente do Setor Público, formada, sobretudo, pelos mais pobres e pessoas sob as demais situações de vulnerabilidade, a PEC Emergencial, que potencializa os efeitos da EC 95, tende a agravar a dramática desigualdade e a crise econômica, social e sanitária vivenciada no país.

Contudo, mesmo com o retorno à trajetória de equilíbrio fiscal, segundo os parâmetros da LRF, a implementação desta agenda de ajuste ultraliberal descortina, para o futuro do ERJ, a perspectiva de progressivo sucateamento e privatização dos serviços 
públicos estaduais, em particular a saúde e a educação, além da degradação da segurança pública e da mobilidade urbana, que afeta, mais intensamente, a qualidade de vida das maiores cidades e, em especial, da Região Metropolitana do Rio de Janeiro.

\section{REFERÊNCIAS}

BRANDÃO, C. A. Crise e rodadas de neoliberalização: impactos nos espaços metropolitanos e no mundo do trabalho no Brasil. Cadernos Metrópoles, v. 19, n. 38, 2017.

BRANDÃO, R. V. da M. O PROES e a Privatização dos Bancos Estaduais. In: SIMPÓSIO NACIONAL DE HISTÓRIA, 25., 2009, Fortaleza. Anais [...]. Fortaleza: ANPUH, 2009. Disponível em: https://anpuh.org.br/uploads/anais-simposios/pdf/201901/1548772005_adf83124319e5fa5b6bfb10d220fef86.pdf. Acesso em: 12 mar. 2021.

BRASIL. Constituição da República Federativa do Brasil de 1988. Disponível em: http://www.planalto.gov.br/ccivil_03/constituicao/constituicao.htm. Acesso em: 12 mar. 2021.

Lei Complementar $n^{\circ} 101$, de 4 de maio de 2000 (Lei de Responsabilidade Fiscal). Estabelece normas de finanças públicas voltadas para a responsabilidade na gestão fiscal e dá outras providências. Disponível em: http://www.planalto.gov.br/ccivil_03/LEIS/LCP/Lcp101.htm. Acesso em: 15 set. 2018.

Lei Complementar $\mathrm{n}^{\mathbf{0}} 159$, de 19 de maio de 2017. Institui o Regime de Recuperação Fiscal dos Estados e do Distrito Federal e altera as Leis Complementares $n^{\circ} 101$, de 4 de maio de 2000, e $n^{\circ}$ 156, de 28 de dezembro de 2016. Disponível em: http://www.planalto.gov.br/ccivil_03/leis/LCP/Lcp159.htm. Acesso em: 15 set. 2018.

. Lei Complementar $n^{\circ} 178$, de 13 de janeiro de 2021. Altera a Lei Complementar no 159, de 19 de maio de 2017 e dá outras providências. Disponível em: https://www.in.gov.br/en/web/dou/-/lei-complementar-n-178-de-13-de-janeiro-de-2021298911357. Acesso em: 12 mar. 2021.

Lei $\mathrm{n}^{\circ}$ 5.172, de 25 de outubro de 1966 (Código Tributário Nacional). Dispõe sobre o Sistema Tributário Nacional e institui normas gerais de direito tributário aplicáveis à União, Estados e Municípios. Disponível em: http://www.planalto.gov.br/ccivil_03/leis/15172compilado.htm. Acesso em: 12 mar. 2021.

LOPREATO, L. F. C. Governos estaduais: O retorno a debilidade financeira. Campinas: Unicamp, mai. 2018 (Texto para Discussão, n. 338). 
MONTEIRO NETO, A. Governos estaduais no federalismo brasileiro: capacidades e limitações no cenário atual. In: (Org.). Governos Estaduais no Federalismo Brasileiro: capacidades e limitações governativas em debate. Brasília: IPEA, 2014.

MORA, M. Federalismo e Dívida Estadual no Brasil. Rio de Janeiro: IPEA, 2002 (Texto para Discussão). Disponível em: https://www.ipea.gov.br/portal/images/stories/PDFs/TDs/td_0866.pdf. Acesso em: 12 mar. 2021.

RIGOLON, F.; GIAMBIAGI, F. A renegociação das dívidas e o regime fiscal dos estados. Rio de Janeiro: BNDES, 1999 (Texto para Discussão). Disponível em: https://web.bndes.gov.br/bib/jspui/bitstream/1408/13514/2/Td-

69\%20Renegociação\%20das\%20dividas\%20e\%20regime\%20fiscal\%20dos\%20estados.\%20 _P_BD.pdf. Acesso em: 12 mar. 2021.

RIO DE JANEIRO (Estado). Lei Complementar n 176, de 30 de junho de 2017. Estabelece normas e diretrizes fiscais no âmbito do Regime de Recuperação Fiscal do Estado do Rio de Janeiro. Disponível em: http://alerjln1.alerj.rj.gov.br/contlei.nsf/a99e317a9cfec383032568620071f5d2/351f497288c8 22cf8325818b005cf117? OpenDocument. Acesso em: 12 mar. 2021.

Lei Complementar $n^{\circ} 9.000$, de 09 de setembro de 2020. Lei de Diretrizes Orçamentárias $\quad$ - $\quad$ LDO $2021 . \quad$ Disponível em: http://www.fazenda.rj.gov.br/sefaz/content/conn/UCMServer/uuid/dDocName\%3aWCC4200 0012364. Acesso em: 12 mar. 2021.

Lei $\mathrm{n}^{\circ}$ 6.243, de 21 de maio de 2012. Institui o Regime de Previdência Complementar no âmbito do Estado do Rio de Janeiro, fixa o limite máximo para a concessão de aposentadorias e pensões de que trata o Artigo 40 da Constituição Federal, autoriza a criação de entidade fechada de previdência complementar, na forma de fundação, e dá outras providências. Disponível em: http://alerjln1.alerj.rj.gov.br/contlei.nsf/3f9398ab330dbab883256d6b0050f039/0b9cd84264bf 426483257a060069b1ba?OpenDocument. Acesso em: 12 mar. 2021.

Lei $n^{\circ} 7.529$, de 07 de março de 2017. Autoriza o Poder Executivo a alienar ações representativas do capital social da Companhia Estadual de Águas e Esgotos CEDAE, e dá outras providências. Disponível em: http://alerjln1.alerj.rj.gov.br/CONTLEI.NSF/c8aa0900025feef6032564ec0060dfff/7bc7d46b5 45146a1832580df005fb7ad?OpenDocument\#: :text=Lei\%20Ordin\%C3\%A1ria\&text=LEI\% 20N\%C2\%BA\%207529\%20DE\%2007\%20DE\%20MAR\%C3\%87O\%20DE\%202017.\&text $=$ AUTORIZA $\% 200 \% 20$ PODER $\% 20$ EXECUTIVO $\% 20$ A,CEDAE $\% 20 \mathrm{E} \% 20 \mathrm{D} \% \mathrm{C} 3 \% 81 \% 2$ 0OUTRAS\%20PROVID\%C3\%8ANCIAS. Acesso em: 12 mar. 2021.

Lei $\mathrm{n}^{\circ} 7.628$, de 09 de junho de 2017. Altera dispositivos da Lei $\mathbf{n}^{\mathbf{0}} \mathbf{5 . 2 6 0}$, de 11 de junho de 2008, da Lei $n^{\circ}$ 3.189, de 22 de fevereiro de 1999, e dá outras providências. Disponível em: http://alerjln1.alerj.rj.gov.br/contlei.nsf/e9589b9aabd9cac8032564fe0065abb4/6451bcf583aa 
a1fb8325813d00686e74?OpenDocument\#: :text=\%C2\%A7\%202\%C2\%BA\%20Concorrend o\%20as\%20condi\%C3\%A7\%C3\%B5es, e\%20vantagens\%20inerentes\%20ao\%20cargo.

Acesso em: 12 mar. 2021.

. Lei $\mathrm{n}^{\circ}$ 7.629, de 09 de junho de 2017. Dispõe sobre o Plano de Recuperação Fiscal do Estado do Rio de Janeiro e dá outras providências. Disponível em: http://alerjln1.alerj.rj.gov.br/CONTLEI.NSF/c8aa0900025feef6032564ec0060dfff/9a0490a99 a2b0d6e8325813d0069556f?OpenDocument. Acesso em: 12 mar. 2021.

Lei $\mathrm{n}^{\mathbf{0}}$ 7.659, de 24 de agosto de 2017. Altera a Lei $\mathbf{n}^{\mathbf{0}} \mathbf{7 . 4 2 8}$, de 25 de agosto de 2016, que institui o Fundo Estadual de Equilíbrio Fiscal do Estado do Rio de Janeiro. Disponível em: http://alerjln1.alerj.rj.gov.br/contlei.nsf/c8aa0900025feef6032564ec0060dfff/f56e84f10f1219 d38325818b005f006f?OpenDocument\#: :text=Lei\%20Ordin\%C3\%A1ria\&text=LEI\%20N\% C2\%BA\%207659\%20DE\%2024,ESTADO\%20DO\%20RIO\%20DE\%20JANEIRO. Acesso em: 12 mar. 2021.

Decreto $\mathrm{n}^{\circ}$ 45.692, de 17 de junho de 2016. Decreta estado de calamidade pública, no âmbito da administração financeira do Estado do Rio de Janeiro, e dá outras providências. Disponível em: http://www.fazenda.rj.gov.br/sefaz/content/conn/UCMServer/path/Contribution\%20Folders/s ite_fazenda/legislacao/tributaria/decretos/2016/DECRETO\%20N.\%C2\%BA\%2045692\%20D E\%2017\%20DE\%20JUNHO\%20DE\%202016.htm. Acesso em: 12 mar. 2021.

Relatório de Gestão Fiscal. Portal Transparência Fiscal do Governo do Estado do Rio de Janeiro. 2021. Disponível em: http://www.transparencia.rj.gov.br/transparencia/faces/sitios-transparencianavigation/menu_sitios_execucaoOrcamentaria/ExecucaoDespesas?_afrLoop=10990177607984446\&datasource=UCMServer\%23dDocName\%3AWC C275683\&_adf.ctrl-state=owcpqus1s_126. Acesso em: 12 mar. 2021 . 